\title{
Artículo
}

\section{Brevísima historia de la lectura electrónica}

\author{
Por Fernando Pérez Arranz
}

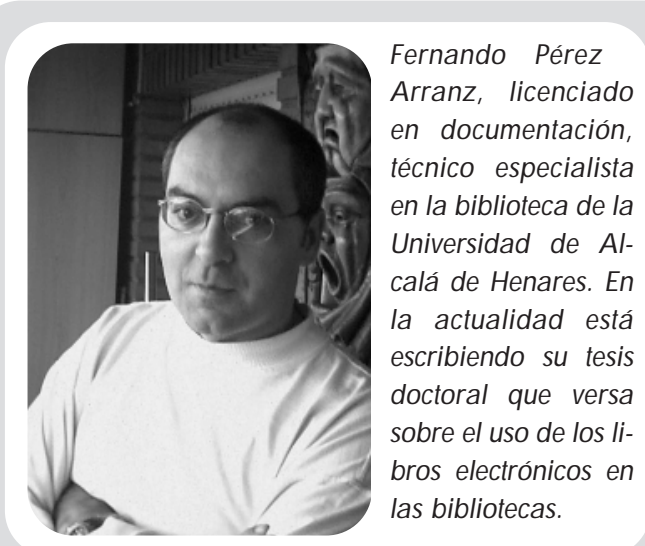

Resumen: La idea de leer sobre pantallas y de las bibliotecas virtuales nos puede parecer algo тиy пиеvo, pero existe una serie de antecedentes que han ido perfilando el concepto hasta convertirlo en lo que conocemos hoy. Aquí se muestran algunos de los pasos que han seguido los libros electrónicos en su breve andadura.

Palabras clave: E-book, Libros electrónicos, Bibliotecas digitales, Bibliotecas virtuales, Historia.

\section{Title: Abbreviated history of electronic reading}

Abstract: The idea of reading on screens and in virtual libraries seems very new, but there are precedents that have developed this concept up to what we know today. This article describes some of the stages electronic books have passed through in their short existence.

Keywords: E-book, Electronic book, Digital libraries, Virtual libraries, History.

Pérez Arranz, Fernando. "Brevísima historia de la lectura electrónica". En: El profesional de la información, 2004, mayo-junio, v. 13, n. 3, pp. 179-190.

La idea de la edición electrónica y de lectura sobre pantalla no es tan nueva como podemos imaginar. Se trata simplemente de un estadio más dentro de la evolución del libro para su difusión en masa, que ya iniciara Johannes Gutenberg con la invención de la imprenta en 1455 .

De esta biblioteca intangible, pero en la que cabe todo el saber universal, han existido diversas pinceladas, no sólo en el campo de la ciencia, como cabría deducir, sino dentro de la literatura. Podemos encontrar la visionaria idea de aglutinar todo el conocimiento humano, en una vasta e inmensa enciclopedia electrónica descrita por Herbert George Wells en 1938, en su obra El cerebro del mundo. Jorge Luis Borges nos describe en su Libro de arena un extraño libro con un número infinito de páginas, que no tenía ni principio ni fin. Éste es denominado la biblioteca interminable o el libro de los libros y se acerca mucho a la idea de inconsistencia y falta de linealidad que ahora tenemos en los libros electrónicos. En el cine también encontramos ejemplos: en Minority report (2002) Steven Spielberg nos describe una sociedad del año 2050 donde la gente que va en el metro lee diarios y revistas electrónicas con páginas dinámicas y cambiantes que se parecen bastante a la idea de e-ink. Durante esta breve andadura que ha tenido la lectura electrónica, no todas las ideas visionarias o los sueños, como el Memex, el NLS o el Dynabook han podido materializarse físicamente. Pero su puesta en práctica y experiencia nos han legado una impronta; utópica y de ciencia ficción en su momento, pero reconocible en muchos de los aparatos con los que trabajamos hoy en día. Lo que se muestra a continuación es una relación cronológica de las principales iniciativas que han dado lugar a lo que hoy conocemos por libros electrónicos.

\section{Memex}

Uno de los padres de la edición electrónica, al menos en sentido conceptual fue el canadiense Vannevar Bush (1890-1974) en el muy temprano año de 1945. Bush propuso el Memex (Memory Extender); un concepto de máquina que almacenaría y manipularía enormes cantidades de información interrelacionada, basándose en los modelos de asociación de la mente humana. Esta máquina serviría para implementar el intelecto humano (de ahí su nombre) y en su mecanismo crearía caminos, enlaces que llevasen de unas partes documentales a otras mediante asociaciones lógicas. Por ello se dice que fue el primero que visionó el concepto de hipermedia (figura 1).

Tenía el aspecto de un escritorio y era un sistema de almacenamiento de la información (cualquier docu- 


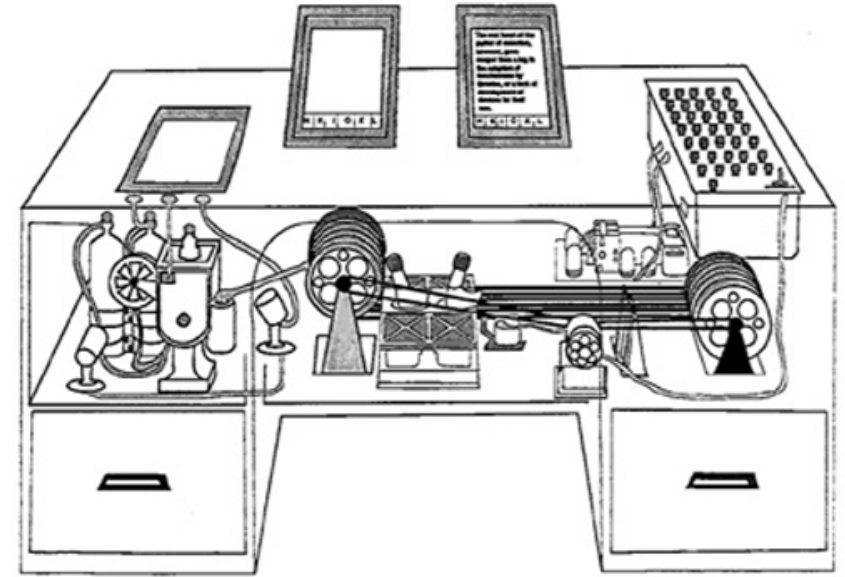

Figura 1

mento: libros, fotografías, etc.) en forma de microfilms. A modo de las ventanas de los ordenadores de hoy en día, el Memex mostraría diversas páginas a un tiempo. También permitía introducir nueva información de libros, dibujos e incluso anotaciones marginales a mano. Las enormes cantidades de información que serían volcadas en él tendrían que ser organizadas no por orden alfabético, numérico ni de otro tipo, sino por asociación de ideas, las cuales estarían interrelacionadas entre sí a partir de índices asociativos que establecieran enlaces entre ítems de información y moverse entre lo que conceptualmente estuviera relacionado. Este tipo de artilugios serían para Bush indispensables para manejar los descomunales volúmenes de material informativo y permitirían crear caminos a través del complejo tejido creado entre distintas unidades informativas que guardaran algún vínculo con respecto a algún punto de vista o perspectiva.

Esta visión de Bush sobre la forma en que debería ser almacenada la información refleja de manera bastante fidedigna el ordenador personal como dispositivo de almacenamiento y recuperación de una información previamente indexada. El Memex pone de manifiesto además la estructura en que hoy se almacenan los textos electrónicos con sistema de enlaces hipertextuales y en particular cómo está estructurada y almacenada la información en internet. Por todo ello se considera que fue el primer concepto de libro electrónico.

\section{Engelbart y el Augment}

Los desarrollos en el campo de la informática llevados a cabo por Douglas C. Engelbart le han llevado a ser llamado el "Edison de los ordenadores personales" ya que es el responsable de la invención del ratón en 1964, del sistema de ventanas (windows), del procesador de textos, de la ayuda en línea y de lo que hoy conocemos por groupware o sistema de participación y comunicación de redes telemáticas. Pero el reconocimiento público le llegó en los últimos años de su vida, con la difusión de la world wide web, después de que su creador, Tim Berners-Lee, hablara del trabajo de Engelbart como antecedente directo del suyo.

Dentro de la edición electrónica en 1962, Engelbart escribe "Augmenting human intellect: a conceptual framework", donde reflexiona sobre las implementaciones y mejoras que deberían tener aquellos incipientes ordenadores y programas para mejorar su rendimiento y aumentar la capacidad cognitiva del ser humano. En esa línea trabaja en el Standford Research Institute, donde pretende desarrollar el proyecto hipertextual NLS (oNLine System), un complejo sistema informático basado en el Memex de Bush. Bajo su inspiración, este proyecto se basa en un aparato mediante el cual, utilizando nuevos instrumentos informáticos y métodos de organización de los conocimientos, pretende potenciar y aumentar la capacidad intelectual de los hombres.

\section{«Douglas C. Engelbart es el responsable de la invención del ratón en 1964, del sistema de ventanas (windows), del proce- sador de textos, de la ayuda en línea y de lo que hoy conoce- mos por groupware»}

En 1968 Engelbart presenta su sistema $N L S$ y que más tarde evolucionaría hacia el Augment (A Conceptual Framework for the Augmentation of Man's Intellect) y constituye el primer sistema para la creación de hipertextos. Este modelo incorporaba un interfaz interactivo y permitía conectar a diferentes usuarios simultáneamente que podían viajar entre la información utilizando ventanas y con la ayuda del ratón.

Además, esta tecnología hipermedia integra mediante hiperenlaces grandes volúmenes de documentación que se generan durante las diferentes fases de un proyecto, manteniendo la consistencia de la información y permitiendo la navegación entre los bloques de texto que interesen en cada momento.

A raíz del reconocimiento público que publicitó Berners-Lee, Engelbart recibió premios por su trayectoria investigadora en 1997 y 2000, incluyendo la Medalla Nacional de Tecnología de EUA.

\section{EI hipertexto y Xanadú}

En 1965 Theodor Holme Nelson, basándose en investigaciones de Engelbart, acuña el término que llegará hasta nuestros días: "hipertexto", y lo hace público en un artículo dirigido a la Association for Computing Machinery ( $A C M)$. En él proponía la utilización de "zippered lists" para relacionar elementos del texto 
(palabras o frases) dentro del mismo texto o con otros diferentes. Con ello proponía una manera de leer y escribir distinta a la que ha existido hasta ahora. Estos textos estaban compuestos al modo tradicional, pero el hipertexto hace que se pierda su orden secuencial y lineal pudiendo seguir distintos caminos gracias a los enlaces.

En 1967 junto a Andies van Dam de la Brown University y otros investigadores, construyen el primer sistema hipertextual: el Hypertext Editing System. Fue un sistema muy revolucionario a finales de los años 60 y es utilizado por este equipo de científicos como herramienta en la docencia. Permitía, dentro de una red intranet del campus, navegar entre textos, relacionándolos, añadiendo datos, etc., dentro de una estructura hipertextual. Este sistema fue vendido al Manned Spacecraft Center de Houston, que lo utilizó para editar documentación de las misiones espaciales Apollo. Después, y como subproducto del Hypertext Editing System, surgiría en 1968 el Fress (File Retrieval and Editing System), del que se hizo una demostración en la ACM Hypertext Conference de 1989.

Pero Nelson es más conocido por su concepción del proyecto Xanadú, un sistema informático basado en la organización no secuencial de textos. El mundo de la computación en la década de los 60 comenzaba a manifestarse como una ciencia incipiente con un sinfín de posibilidades potenciales y que atraía a diversos jóvenes con sus rudimentarios lenguajes de programación. En esta época se acuña el término hacker, que se relacionaba en un sentido positivo con estos adolescentes idealistas que, como Ted Nelson, buscaban un mundo mejor, más igualitario a la sombra de la tecnología y donde el derecho a la información y al uso generalizado de los ordenadores fuera una realidad.

\section{«Licklider escribió en 1965 'Li- braries of the future', donde predijo, con bastante tino, que las bibliotecas digitales serían una realidad alrededor del año 2000»}

Con esta idea, y con las reflexiones de Vannebar Bush y su Memex, nace el proyecto Xanadú. Se basaba en una amplia red de ordenadores interconectados a un ordenador central, donde todos tendrían total comunicación entre sí desde cada terminal y acceso sin límites a una vasta cantidad de información. Dentro de este universo, y gracias al hipertexto, cada documento estaría ligado a otros y así, desde un texto poder acceder a todos con los que guardara relación. Xanadú nació en 1965 y era desarrollado por un grupo de hackers colaboradores de Nelson sin sueldo. Según ellos, $\mathrm{Xa}$ - nadú cambiaría radicalmente la forma de producir y recibir información en todo el mundo, si bien nunca llegó a concretarse salvo en algunas demostraciones de un software sin pulir demasiado, que no terminó de convencer a los inversores. Únicamente Autodesk Inc. lo comercializó de 1989 a 1992 sin mucho éxito.

En 1981 Ted Nelson publica "Literary machines", donde resume y conceptualiza su sistema junto con sus ideas de acceso libre a la información gracias a las redes de ordenadores. Es un manifiesto de la revolución digital para la cultura hacker y él mismo pretendía ser un ejemplo de hipertextualidad en un medio impreso: el libro no tenía índice ni nada que permitiera seguir una secuencia con oraciones interrumpidas que después seguían en otra página.

\section{Licklider, 1965}

Joseph Carl Robnett Licklider constituyó otro de los grandes pilares dentro del desarrollo de la edición electrónica. Estudia su licenciatura en psicología, aunque en 1950 empieza a trabajar en los laboratorios del MIT donde se familiariza con la informática dentro de los diseños de planes de defensa en el contexto de la guerra fría. Introducirse en el mundo de la informática desde la base de la psicología le daba una perspectiva única. Gracias a ella escribe en 1965 Libraries of the future donde teoriza sobre la forma en que la información debe ser almacenada y hace un atrevido pronóstico acerca de la edición electrónica. En esos lejanos días predijo, con bastante tino, que las bibliotecas digitales serían una realidad alrededor del año 2000. En el prefacio, Licklider dedicó su libro Libraries of future a Vannebar Bush por la inspiración que le sobrevino al leer su artículo "As we may think" y que le ayudó a preparar este trabajo.

Él concebía el uso de los ordenadores en la gestión, almacenamiento y difusión de la información y le preocupaban los enormes volúmenes de conocimiento frente a la capacidad de las memorias informáticas y la velocidad de los procesadores. Licklider acuñó el término "sistemas precognitivos" para nombrar el sistema del futuro que él predijo reuniría muchas disciplinas, mezclando ciencias informáticas, sociales y de conducta, bibliotecarias y almacenaje de información y estudios de recuperación para formar un modelo que beneficiara a la humanidad. Este sistema precognitivo se parece mucho a lo que hoy conocemos como world wide web.

Además, dentro de la Advanced Research Projects Agency (ARPA), concibe y diseña en 1969 el funcionamiento de la red Arpanet para el Departamento de Defensa de EUA, dentro del contexto de guerra fría de la época. Consiste en una red de ordenadores remotos interconectados entre sí, que más tarde se convertiría en 
la actual internet. Este hecho constituye el principal medio de difusión de textos digitales y por tanto embrión de la lectura electrónica.

\section{Dynabook}

El nacimiento del libro electrónico portable, o al menos de un aparato ideado para la lectura de textos en una pantalla, comenzó en el año 1968 cuando Alan Kay desarrolló el concepto de Dynabook, como "un ordenador personal interactivo portátil, tan accesible como un libro". Considerando que lo dijo muchos años antes de la llegada del ordenador personal y de internet, su ordenador capaz de comunicarse sin cables era una idea visionaria. Se basaba en la necesidad de que los alumnos pudieran disponer de los libros de texto y el material didáctico en cualquier lugar.

Su tesis doctoral fue premiada por ser el desarrollo de la primera interfaz gráfica, y al año siguiente se incorporó al equipo de investigadores del Centro de Investigación Xerox de Palo Alto (PARC) en California. Allí participó en la creación de interfaces gráficas de usuario pensando en la mentalidad de los niños. Del Dynabook y su entorno gráfico surgió una serie de elementos que son parte de cualquier ordenador de hoy día, como los menús desplegables e iconos que más tarde Apple y después Microsoft ampliaron; y su lenguaje de programación orientado a objetos, el Smalltalk, que luego se convertiría en el Hypertalk de Apple.

Pero a Alan Kay se le recuerda por el concepto de Dynabook, que según su idea debía de pesar menos de un kilo, poder mantenerse sobre las piernas del usuario, utilizar una pantalla muy delgada, contar con un teclado y un lápiz, reconocer la escritura de la mano del usuario y comunicarse de forma inalámbrica.

Hubo que esperar hasta 1984 para ver la primera versión comercial con el nombre de ordenador personal Grid, creado por una empresa joven fundada en 1979 por dos investigadores de la $P A R C$, Glenn Edens y John Ellenby. Inspirado en la visión de Kay, el Grid incorporaba muchas innovaciones que ahora nos parecen comunes, tales como módem interno o el ya familiar diseño en forma de concha que le permite cerrarse para proteger la pantalla.

Mas tarde evolucionó hacia el Toshiba's Dynabook en 1991, gracias a que esta firma ofrecía unas pantallas verdaderamente extraplanas $(L C D)$. El nombre de $D y$ nabook fue utilizado únicamente en Japón y fue el primer ordenador portátil, aunque no sólo servía para leer textos electrónicos. Este aparato era en realidad una pantalla táctil, transparente como un cristal, y exenta de teclado, que se conectaba a un ordenador. Este libro dinámico es un aparato de sólo lectura conectado a un ordenador que ejercía de disco duro. Utilizaba también discos flexibles de 3,5" y tenía un disco duro de $20 \mathrm{MB}$, si bien uno de sus grandes logros era su pantalla táctil.

El Dynabook podía manejar textos e imágenes y estaba diseñado para que fuera manejado por niños a través del uso del lenguaje Paintbrush que permitía crear imágenes y animarlas. Después, en Apple, su visión del Dynabook se transformó en realidad, tomando la forma del Apple Newton MessagePad; era 1993 y apareció el primer PDA del mundo. El Newton era capaz de mostrar títulos electrónicos en formato NewtonBook; incluso se produjeron de forma bastante discontinua cientos de libros electrónicos.

\section{GML. EI primer lenguaje de marcas}

En $I B M$, en 1969 se desarrollan los primeros trabajos de los lenguajes de marcado para estructurar documentos electrónicos que hoy conocemos como html o xml. Todos ellos derivan del sgml (Standard Generalized Markup Language) y es el estándar ISO 8879 del Instituto Internacional de Estandarización que apareció en 1986. Pues bien, en 1969 nació su antecesor, el GML (General Markup Language) bajo la dirección de Charles Goldfard. Junto a él trabajaron Edward Mosher y Raymond Lorie (nótese que las iniciales de sus apellidos coinciden, se cree que deliberadamente, con el nombre del lenguaje). El GML fue un intento de resolver los problemas asociados al tratamiento de documentos en diferentes plataformas, ya que cada aplicación utilizaba sus propias marcas para describir los diferentes elementos. Las marcas o etiquetas son códigos que indican a un programa cómo debe tratar su contenido y así delimitar la forma en que aparecerá en la pantalla o por la impresora.

Fue diseñado al igual que sus sucesores como un metalenguaje: esto es, para componer estructuras de datos que describen a otros. Con su evolución se ha utilizado en muchísimas aplicaciones siendo la más conocida la de confección de páginas web. Por supuesto, dentro de la edición digital es muy importante al permitir definir la manera en que se deben construir los bloques textuales. En estas primeras versiones de $I B M$, el GML también era conocido por DCF (Document Composition Facility).

El consorcio Open e-Book (OEB) se creó para definir estándares y poner un poco de orden dentro de la variedad de formatos propietarios de e-book. En el desarrollo de estos formatos estandarizados, la $O E B$ se está basando en el xml, un lenguaje no propietario evolución del sgml.

\section{EI Proyecto Gutenberg}

Supuso el primer proyecto de biblioteca electrónica de la historia y los primeros pasos para el fomento 
de libro electrónico. Michael Hart, un estudiante de la Materials Research Lab. de la Universidad de Illinois, recibió la inusual beca de 100 millones de US\$ en tiempo de uso del ordenador del departamento para desarrollar algún proyecto de aplicación informática. Reflexionó sobre las ventajas que supondría la posibilidad de volcar en un ordenador todo el conocimiento depositado en las bibliotecas. Así comenzó en 1971 el Proyecto Gutenberg y el primer texto que introdujo tecleándolo a mano fue, cómo no, La Declaración de Independencia de los Estados Unidos para que fuera accesible a todos los norteamericanos. En ese momento había unos cien ordenadores conectados a la red Arpanet, predecesora de internet. Así se continuaron almacenando textos clásicos y, en general, las grandes obras de la humanidad cuyos derechos de propiedad intelectual habían prescrito. En EUA, por presiones de las grandes editoriales, la edad de prescripción de sus derechos de propiedad intelectual ha sido aumentada en dos ocasiones y ahora está en 95 años después de la muerte del autor. Así Michael Hart redactó una lista de títulos de libros con una antigüedad desde 2.500 años hasta 100. Una sección del Proyecto Gutenberg se ocupa de ver cada año qué libros tienen sus derechos de propiedad caducados para ser incluidos en esta biblioteca. También ha introducido algún título más reciente, porque se ha hecho con el permiso de autores $\mathrm{y}$ editores.

Los primeros textos electrónicos eran transcritos por voluntarios ubicados en distintos países que los tecleaban para ponerlos a disposición de cualquiera en la Red. Así, la propuesta de Michael Hart era doble: por un lado creaba la primera biblioteca digital que difundía gratuitamente el saber con lo que supone de desafío al mercado editorial, mientras que por otro lado invitaba a la reflexión sobre las posibilidades de las nuevas tecnologías.

Estas iniciativas altruistas sobre difusión de la cultura escrita a cualquiera fueron posibles gracias a la aparición de internet. Por supuesto la lengua predominante es el inglés, aunque podemos encontrar traducciones a ese idioma de los clásicos de nuestra literatura como Lope, Cervantes, etc. También encontraremos las obras de nuestros clásicos en español, así como textos en francés, italiano, latín, etc.

Para conseguir la universalidad que se persigue, el formato de todos los textos está en texto plano ascii, que es el más simple y legible por cualquier ordenador y con cualquier programa de texto, aunque sea una versión antigua. Así, estos textos tampoco tienen estructura alguna ni cuentan con ninguna etiqueta que podamos encontrar en otros textos digitales. Además, hay que señalar que en estas iniciativas hay un mayor interés por acumular bits que por una necesaria orde- nación de las obras entre los grandes volúmenes de texto. Como este proyecto existe en la actualidad un buen número de iniciativas similares en distintos países. En España es obligado señalar la excelentemente realizada Biblioteca Virtual Miguel de Cervantes o en Francia el Proyecto Gallica, aunque hay muchos más. En el Electronic Text Center de la Universidad de Virginia podemos encontrar, entre otras muchísimas cosas, a nuestros clásicos en nuestro idioma.

\section{Los floppy books}

Durante las décadas de los 80 y 90 tuvo lugar un gran número de intentos de digitalizar textos escritos y ofrecerlos en formato de bits. Eran ofertados en los soportes de la más avanzada tecnología de la época: los videodiscos, los flopy discs y por supuesto el cd-rom de $8(3,1 ")$ y $12 \mathrm{~cm}(4,7 ")$.

El primer soporte transportable de los libros electrónicos fueron los discos flexibles con ficheros comprimidos que podían ser instalados en los discos duros de aquellos ordenadores. Aquí podemos encontrar $\mathrm{Hy}$ pertext hand on, distribuido en 2 disquetes de 5,25". También diversos diccionarios, como Collins electronic English dictionary and thesaurus, en 7 disquetes de 3,5"; o el Diccionario electrónico Random House que sale a la calle en 1981, para muchos el primer libro electrónico con fines comerciales.

\section{«En 1984 el Grid incorporaba muchas innovaciones que aho- ra nos parecen comunes, tales como módem interno o el ya fa- miliar diseño en forma de con- cha que le permite cerrarse pa- ra proteger la pantalla»}

Pero uno de los más grandes pasos en la edición electrónica y en la aparición de novelas en este formato, fue el Proyecto Voyager y sus expanded books. Se inició en el verano de 1990 y lanzó una colección de novelas destinadas a ser leídas en un ordenador, muchas de ellas distribuidas en disquetes y otras en cdrom. Publicadas en formato comprimido, estos textos digitales incluían algunos recursos como sonido y vídeo. Entre sus títulos figuran Jurassic Park. A voyager expanded book, escrito por Michael Crichton (Santa Monica, 1990) o Comic book confidential (1994), ambas editadas en formato Macintosh.

Editada por Penguin en 1994 sobre disquetes de 3,5, Host es una novela de ciencia ficción que, aparte del texto electrónico, incluye un vídeo del autor, Peter James, presentando su obra. Contiene además un epílogo en audio donde resume los últimos adelantos en el campo de la crionización — congelación de personas 
recién fallecidas- y una charla sobre la interacción entre el hombre y los ordenadores. Host tiene 83 capítulos con un total de 1.515 páginas y se podía instalar en el disco duro de un Macintosh.

Estas obras podían ser leídas sobre tarjetas HyperCard para los primeros Apple Power Books de Macintosh, del que hablaremos más adelante.

\section{EI cd-rom, 1980}

Las empresas Sony y Philips dan a conocer el nuevo disco compacto o cd-rom, que permite el almacenamiento digital, en principio de sonidos (cd-da, disco compacto audio digital). Hasta ahora mismo, y hasta que el DVD se implante como medio de difusión, ha sido el soporte más utilizado. Si bien es un soporte más que un aparato lector, es necesario nombrarlo, junto con el DVD por su gran utilidad dentro de los sistemas de almacenaje portátil de información. Existen en dos tamaños: los de 12 y $8 \mathrm{~cm}$ de diámetro. La capacidad de almacenaje es de 650 y $200 \mathrm{MB}$ respectivamente.

Por el contenido del cd-rom podemos clasificarlos en tres categorías básicas: los que a la vez que educan, entretienen o "edutainment", las bases de datos y las obras de referencia.

Los sistemas de recuperación de información en cd-rom intentan servir tanto para reemplazar como para suplir los servicios correspondientes dados previamente online, usando módems conectados a redes de telecomunicación. En las bibliotecas y centros de información de los 90 se hicieron muy populares aunque uno de sus grandes problemas era su carencia de interfaz estándar. Ejemplos de este tipo de sistemas pueden ser encontrados todavía hoy en día, e incluían Science Citation Index, Lisa Plus, MLA, WinSpirs Medline, etc.

Pero el cd-rom propició un enorme aumento en la edición en formato hipermedia y multimedia; el comienzo de la década de los 90 coincide con la incorporación masiva de los cd-rom a los ordenadores personales. Aparecen diversas aplicaciones informáticas orientadas a integrar texto, sonido e imagen; y por otro lado a interconectar estos elementos posibilitando al usuario el acceso no lineal y selectivo de la información multimedia.

Microsoft lanzó sus Enciclopedias Microsoft, entre cuyos productos podemos encontrar Multimedia Stravinsky, Art Gallery, Multimedia Mozart, Cinemania y por supuesto la muy difundida Encarta. Desde sus primeras entregas, la Enciclopedia Encarta contenía además del texto, gráficos de calidad, sonido y vídeo. $\mathrm{Ci}$ nemania contenía también escenas en vídeo de diversas películas junto a sus bandas sonoras. Dentro de $M i$ crosoft también podíamos encontrar Microsoft Books- helf que era una biblioteca de consulta que contenía 7 obras en un único cd: The American heritage dictionary, Roget's thesaurus, The world almanac and book of facts, Barlett's familiar quotations, The concise Columbia dictionary of quotations, The concise Columbia encyclopedia y The Hammond atlas.

También fue relevante The Viking opera guide, editada por Penguin. Se trataba de una obra en $12 \mathrm{~cd}$ roms con información de 800 compositores, examinaba 1.500 óperas con 3 horas de música y más de 300 imágenes.

En España, como en otros países, las primeras obras son editadas por empresas ajenas a la edición de libros como Micronet. Pero a partir de 1994 se ven cada vez más productos de origen editorial como Anaya Multimedia, que es una de las pioneras en la edición de libros electrónicos interactivos. Desde los inicios es muy común encontrar obras de referencia cuyo contenido es legislación y jurisprudencia, como la conocida base de datos Aranzadi a texto completo. La editorial Planeta lanzó también distintas enciclopedias como la edición multimedia de su Enciclopedia del arte espa$\tilde{n} o l$ en CD-I. Otras iniciativas son la del Instituto Cervantes que lanzan una obra en un solo cd-rom, dirigida a filólogos donde encontramos el texto íntegro de El Quijote junto a un programa que lo gestiona con índices. El presidente de Microsoft, Bill Gates, al presentar su iniciativa de libro electrónico en la feria Comdex de Las Vegas señaló que desde 1994 se venden más enciclopedias en cd-rom que en papel.

En la década de los 80 había habido una serie de logros en la puesta en escena de libros electrónicos. El Super Book, el Book Emulator y el Hyper Book fueron tres proyectos que reproducían el aspecto y funcionamiento de los libros tradicionales y que conseguían implementar las reducidas capacidades de éste. Estos proyectos fueron diseñados para mejorar el acceso al conocimiento que hay en los libros.

\section{EI proyecto SuperBook, 1989}

En realidad se trata de uno de los primeros prototipos de sistemas para la navegación de hipertexto que mejoraba el tratamiento de los documentos electrónicos. SuperBook comenzó a desarrollarse en 1985 en los laboratorios Bellcore. Los documentos empleados podían ser un único libro o bien un grupo de textos, aunque deben estar escritos con lenguaje de marcas (html) para que SuperBook pueda interpretar su estructura. Una vez que ha sido procesado, el sistema permite navegar por el texto y manejarlo interactivamente buscando, por ejemplo palabras o realizando anotaciones utilizando el ratón. Una vez que el texto se ha incorporado, el programa lo estructura y lo muestra en cuatro ventanas: una para el título del libro, otra pa- 
ra la tabla de contenidos, para la página que se está leyendo y otra para consulta o búsqueda de palabras con un índice de palabras clave. El usuario puede manejar este índice o tabla de contenidos (a la izquierda de la pantalla) usando el ratón para moverse por el texto. Al pasar sobre las secciones, éstas se expandirán mostrando

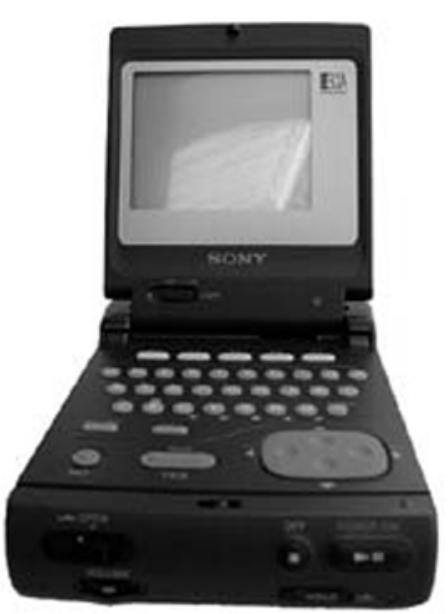

Figura 2 las subsecciones. El usuario también puede seleccionar palabras clave y navegar a través del texto usando el índice. Igualmente sucede con los resultados de las búsquedas, donde las secciones donde están las ocurrencias aparecerán expandidas y en la parte de texto (mostrado a la derecha de la pantalla), las palabras resaltadas (figura 2).

Durante su desarrollo se realizaron algunos estudios y evaluaciones (Landauer et al.) de su comportamiento con los usuarios. Una evaluación se realizó comparando este sistema con la tradicional utilización de la documentación en papel. Para la mayoría de las tareas, las realizadas sobre SuperBook, especialmente a partir de la segunda versión, eran más rápidas y precisas que en el sistema tradicional.

\section{EI Book Emulator}

Otra investigación interesante dentro de los libros electrónicos y su utilización en el apoyo de la enseñanza ha sido descrita por Benest y Jones. Su trabajo describe la creación y el uso de un sistema al que llaman Book Emulator, que funciona sobre una plataforma Unix y es un intento de imitar con precisión los libros en papel utilizando un procedimiento informatizado.

Una publicación de Book Emulator se parece exactamente a un libro abierto. A lo largo de la parte inferior, unos indicadores orientan tanto de la situación actual como del tamaño del libro. La interacción terminal-usuario con un libro tiene lugar usando un ratón (para navegar) y un teclado (para la entrada de datos). De cualquier forma, también se pueden usar anotaciones sonoras e imágenes. Por ejemplo, al pulsar uno de los botones del ratón, conseguimos volver la página; y al pulsar el otro botón la página se vuelve en sentido contrario. Las vueltas de las páginas están animadas para que se parezcan a las de un libro de verdad. Dejando el botón del ratón pulsado, el usuario puede navegar a través del libro. Según se progresa hacia de- lante o hacia atrás en el libro, la imagen de la página que se extiende crece en el lado donde tiene un mayor grosor de páginas y se encoge dinámicamente en el opuesto para darle volumen.

\section{EI proyecto Hyper-Book}

Desarrollos parecidos al Book Emulator se han descrito por Catenazzi y Sommaruga (1994) y Landoni, Catenazzi y Gibb (1993) como parte de su proyecto Biblioteca Electrónica Virtual (VEL). Su sistema Hyper-Book, por ejemplo, está escrito en HyperCard y trabaja con un ordenador Apple Macintosh, componiéndose de dos elementos básicos: una plantilla genérica para generar libros electrónicos (llamada la constructora de hyper-book), y los libros mismos (los hyper-books).

La constructora de hyper-books crea la plataforma donde se elaborarán los hyper-books a través de la importación de un texto que ya existe en formato electrónico. La constructora acepta dos tipos básicos de entradas: texto convencional en ascii y ficheros en formato $\mathrm{sgml}$. La estructura requerida para un hyper-book en concreto se especifica por medio de un Document Type Definition (DTD) dentro del fichero sgml que se usó para crearlo.

\section{«El cd-rom propició un enorme aumento de la edición en for- mato hipermedia y multimedia; el comienzo de la década de los 90 coincide con la incorpo- ración masiva de los cd-rom a los ordenadores personales»}

Los hyper-books mantienen muchas de las características de los libros en papel y presentan la información en un formato lo más parecido posible a éste. Además, se les añaden otras capacidades tales como indización, mecanismos de historia, vínculos activos y demás. Como el Book Emulator de Benest, un hyperbook se presenta en una pantalla como si fuera un documento abierto con dos páginas pegadas, las cuales contienen varios componentes tales como: pie de página, encabezado, márgenes y el texto en sí. Este texto puede contener además notas, dibujos y otros componentes no textuales. Los vínculos reactivos (de hipertexto) de una sección del texto se notan porque la letra cambia. Los hyper-books están dotados de varias funciones de control del libro (tales como vuelta de página, navegar a través de ellas, cerrar el libro, etc.) y tienen cierto número de herramientas de lectura como por ejemplo ayudas de orientación, posibilidades de personalización, búsqueda, historia, navegación y facilidades de impresión. 
Como se ha mencionado con anterioridad, el sistema Hyper-Book es un componente importante para crear libros electrónicos de uso en varios proyectos de bibliotecas electrónicas en los que los autores se han visto envueltos (tal y como el VEL y la investigación de la Super-library que se llevaron a cabo en el Joint Research Centre de la Comisión Europea, Ispra, Italia).

Mientras, en 1986 y dentro de la primera conferencia sobre cd-rom, organizada por Microsoft en Seattle, Owl International (Office Workstation Ltd.) presenta un programa llamado Guide, para la construcción de hipertextos en ordenadores personales. Fue desarrollado en la Universidad de Kent sobre un sistema Unix. En ese año fue cedido a $O w l$ para su explotación comercial. Aparece primero en versión Macintosh y un año más tarde para IBM PC.

Uno de sus aspectos más importantes es que posibilitaba tres tipos de enlaces diferentes:

-Proporciona una estructura jerárquica que se asemeja a la del libro. Al activar, por ejemplo, el título nos muestra el texto de la sección a la que pertenece.

-Permite abrir una pequeña ventana que muestra un pequeño texto explicativo. La ventana desaparece al dejar de apretar el botón del ratón.

- Salta a otro sitio en el hipertexto.

En 1986 Sony también estaba intentando desarrollar su e-book lanzando el Franklin, un aparato que cabía en una mano y era capaz de mostrar una línea sólo en cada momento. Este primer e-libro contenía un diccionario electrónico, con lo que constituye el primer libro electrónico portátil. En 1991 sacaron una nueva versión con teclado y una pantalla que mostraba cuatro líneas. Con este modelo se podía leer la Biblia.

\section{HyperCard}

En 1987, Bill Atkinson presenta el HyperCard, un programa revolucionario hipertextual para Apple, que lo distribuyó gratuitamente a través de Macintosh y que ya hemos mencionado en el modelo Hyper-book. Utiliza el Hypertalk, un lenguaje de programación orientado a objetos de uso muy sencillo, que sin duda fue el motivo principal por el que HyperCard se convirtiera en algo tan popular.

Fue diseñado en su origen como un sistema de pro- gramación en entorno gráfico y no está específicamente desarrollado para la creación ni gestión de textos ni hipertextos. Apple lo convirtió sin querer en un estándar para la creación y estructuración de información textual, debido a que, como hemos dicho, era regalado al comprar un Macintosh entre 1987 y 1992, y que los usuarios de Mac comenzaron a crear con él presentaciones multimedia de manera muy fácil. Precisamente la popularidad de esta herramienta motivó el nacimiento de sucesores como SuperCard, MetaCard, Toolbook, Authorware Professional o Plus.

\section{El Sony Data Discman y el Bookman}

En 1991 Sony desarrolló el Data Discman que leía libros electrónicos editados en soporte cd-rom de 8 centímetros. Permitía almacenar alrededor de 200 MB de texto, imágenes y sonido.

Mas tarde se comercializó en EUA con el nombre de Electronic Book Player, un aparato que cabe en la palma de la mano, de menos de 900 gramos y que albergaba un cd-rom de $8 \mathrm{~cm}$. Poseía capacidad tanto de audio como de texto en cd-rom y podía almacenar 100.000 páginas de texto impreso e incluso gráficos ó 6 horas de música. Existía una amplia oferta de publicaciones que podían ser leídas por el aparato como la Compton's Concise Encyclopedia, la Wellness Encyclopedia y el Passport's World Travel Translator. Para editar documentos que pudieran ser leídos con el Data Discman, los editores debían hacerlo en un formato propietario: el Sony's Electronic Book Authoring System (figura 3).

No era muy fácil de usar, pero permitía buscar información de muchas formas: por un término, por uno más amplio dentro de una lista de ellos, por palabra clave del título de un capítulo o artículo; e incluso permite usar hipertexto. Básicamente el Sony EB Player consistía en una pantalla de cristal líquido $(L C D)$ con

The SuperBook Document Browser Features

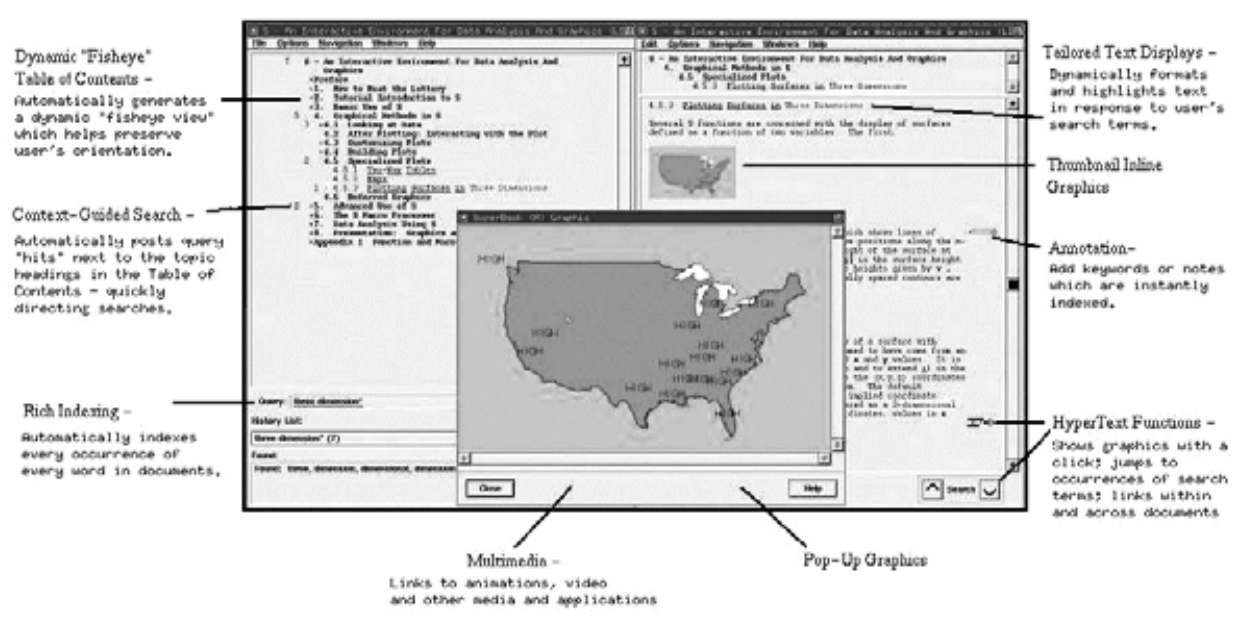

Figura 3 
iluminación trasera, un teclado qwerty (el convencional) ampliado y un cd-rom interno. La pantalla mostraba párrafos de 10 líneas de 30 caracteres. El lector de cd-rom admitía tres formatos de discos compactos: los cd-da (discos convencionales de audio), cd-rom XA (cd de arquitectura extendida que intercala archivos de sonido y datos) así como los discos editados con el estándar ISO 9660, que sólo podían soportar archivos de texto y gráficos básicos.

\section{«En la temprana época de fina- les de siglo se produce una verdadera edad de oro de los ebooks con la aparición simul- tánea aunque desordenada de distintos aparatos»}

El enchufe de salida de audio se puede utilizar para conectarlo a unos auriculares, altavoces o un sistema de amplificación estéreo. La salida del vídeo permite al Sony EB Player conectarse a una televisión o a un grabador de vídeo ordinario, permitiendo por tanto ver el contenido del cd-rom del discman en una pantalla de TV o grabarlo en una cinta de vídeo.

La pantalla tenía un tamaño pequeño (3,5 pulgadas medidas en diagonal) de baja resolución y con unas capacidades multimedia bastante limitadas, con lo que fue rápidamente sustituido por el Bookman, producido primero por Sony y más tarde por Franklin Electronic Publisher en 1992. Tenía una pantalla más grande, 4,5 " y se publicó una gran variedad de materiales de referencia, desde diccionarios en diversas lenguas a colecciones de citas. Era mucho más versátil que el Data Discman ya que no usaba el formato propietario de Sony y podía leer cualquier cd-rom con el formato del sistema operativo DOS.

El Bookman abandona mas tarde el cd-rom y almacena los datos en cartuchos. En esas mismas fechas, Franklin también lanzó el Pocket PDR Medical Book System, un pequeño aparato equipado con un teclado y una pantalla monocromática. Como su nombre indica se trataba de un e-book portátil asistente de médico que contenía una variedad de manuales sobre terapias y otro sobre efectos de fármacos.

Además, Apple introdujo a principios de los 90 un ordenador personal llamado Power Book, con una pantalla más grande y más legible que el Electronic Book Player de Sony. El Power Book no tenía parpadeo y sí una gran gama de contrastes de blancos y negros que se acercaba a la apariencia del papel blanco impreso. En 1992, el Proyecto Voyager, del que ya hemos hablado, fue el pionero en multimedia recreando títulos en cd-rom como Parque Jurásico y Alicia en el País de las Maravillas en HyperCard para el Apple Power. Estas obras tenían sonido y movimiento.

Más tarde Franklin lanzó el eBookMan, un nuevo lector que poseía una pantalla más grande que permitía descargar textos electrónicos desde internet y del que hablaremos más adelante. No obstante, Franklin cuenta con una gran tradición editando libros electrónicos como el eBookManager, basado en las tarjetas BookCards. El usuario podía descargar el texto electrónico vía módem y grabarlo en la tarjeta gracias al software BookMan Writer.

La llegada de los PalmPilots en 1998 puso en el mercado una generación de pequeños y potentes miniordenadores que permitía una gran variedad de posibilidades. De ellos hablaremos más adelante.

\section{EI DVD}

Se ha convertido en el heredero natural del cd-rom, en el sentido de soporte con capacidad de almacenar grandes cantidades de información que puede ser leída en diversos aparatos informáticos. Se ha desarrollado con una capacidad para almacenar 7 veces $(4,7$ GB) la información que cabe en un cd-rom. Esto facilita la lectura de documento multimedia con sonido o imágenes en movimiento.

Dentro de la edición, las últimas producciones multimedia de enciclopedias como la Británica, la Encarta, etc., precisaban de hasta cuatro cd-roms para guardar todo su contenido, que ahora cabe en un sólo DVD. Sobre este soporte, y sólo en el mercado español, encontramos la Historia del arte multimedia Salvat o, en un solo DVD, la base de datos Aranzadi que hasta 1999 se distribuyó en 6 cd-roms. También nos llama la atención por su volumen el Nuevo Tesoro Lexicográfico de la Lengua Española, editado por la Real Academia Española, donde es posible buscar sobre 66 obras lexicográficas de nuestra lengua.

\section{Los libros electrónicos}

Nos encontramos a finales de los 90 y comienza lo que parece, en principio, un despegue de los libros electrónicos. Surge una serie de programas para su lectura sobre ordenadores, e incluso máquinas exclusivamente dedicadas a la lectura electrónica. Esta euforia es acompañada de multitud de iniciativas, (diferentes aparatos, programas y formatos de textos) pero todos son incompatibles y nada intercambiables entre ellos. En 1998, bajo patrocinio del NIST (National Intitute of Standars and Technology) se celebra la primera conferencia mundial del libro electrónico en Gaithersburg, Medford (EUA). Con un fin normalizador se presentó el proyecto Open eBook Forum, un organismo formado por expertos y profesionales tanto de la industria de los libros electrónicos como por representantes de edi- 
tores, autores y usuarios procedentes de diferentes países. Su función sería "crear y mantener estándares que posibiliten el uso generalizado de hardware, software y formato textual en los libros electrónicos" y partía, entre otras iniciativas de uso generalizado de los lenguajes xml y html.

Liderada por los grandes NuvoMedia, SoftBook Press y Microsoft, en enero de 2000 se creó por fin dicho Open E-Book Forum y lo primero que desarrolló fue una serie de medidas destinadas a proteger los derechos de propiedad intelectual contra el pirateo y evitar sobre todo la copia ilícita de los e-textos. Aún no existe ningún estándar común y sí un buen número de formatos de edición y de tipos de lectores; todos ellos incompatibles entre sí. Así, los libros electrónicos que aparecen entre finales y principios de siglo son, en general, metáforas de sus familiares de papel, diseñados para que quepan en una mano y cuentan con pantallas de alto contraste y gran resolución que permiten leer con cualquier condición luminosa: desde una habitación en penumbra (ya que la pantalla tiene luz propia) hasta bajo el sol veraniego en el exterior. Todos aparecen con la posibilidad de realizar anotaciones marginales, subrayar textos o marcarlos fluorescentemente, buscar una palabra dentro del texto o en un diccionario que suele llevar incorporado de fábrica. Por otra parte, permiten también ser personalizados pudiendo cambiar el tamaño y el modelo de la letra mediante unos controles sencillos e intuitivos. Además surgieron programas para convertir cualquier PC en un aparato que leyera libros electrónicos. Los más populares son Microsoft eBook Reader y Adobe eBook Reader.

Entre los aparatos denominados de propósito dedicado podemos encontrar:

- Millenium E-Reader: fue una de las primeras opciones y de las más baratas. Tiene el tamaño de un libro de bolsillo y sólo pesa 500 gramos; además soporta 10 libros de texto e imágenes. Para el Millenium existía el World Bookstore con cientos de títulos a la venta que podían ser bajados mediante un enlace encriptado y seguro a un ordenador para después pasarlos al Millenium E-Reader. Librius no lo mantuvo mucho tiempo en el mercado; no pudieron aguantar la presión de la competencia y prefirieron redirigir su negocio hacia la confección de software para aparatos PDAs.

-Softbook: a partir de 1998 podíamos encontrar el Softbook Reader, de la empresa californiana Softbook Press Inc., fundada en Palo Alto por Jim Sachs y Tom Pomeroy. Se enciende automáticamente al abrir la tapa y simula que se pasa la página. Su pantalla de 6x8 pulgadas (de $15 \times 20 \mathrm{~cm}$ ) sólo muestra una página en blanco y negro (aunque tiene una capacidad para unas
100.000) y es sensible al tacto. Su peso es de 1.300 gramos. El fabricante asegura que puede cargar hasta 250 novelas, aunque la batería apenas puede aguantar 5 horas. No precisaba de ordenador para descargar los textos porque poseía un pequeño módem incorporado (de 33,6 Kbps) y sólo era preciso conectarlo a una línea de teléfono. Se marca automáticamente la dirección del almacén de Softbook Press y muestra los títulos disponibles. Se elige uno Softbook lo carga en la tarjeta de crédito, descargando el libro que permanecerá en él hasta que sea eliminado. Después es posible descargarlo de nuevo, ya que en la cuenta principal del almacén queda registrado el aparato y únicamente se paga una vez. En 1999 el Atheneum de Chicago reconoció sus méritos con el premio del Museo de Arquitectura y Diseño.

-Rocket e-Books: Nuvomedia, creada en 1996 por Martin Eberhard y Marc Tarpenning, comenzó en ese año a fabricar el libro electrónico más difundido: el Rocket eBook. Es también un aparato que cuenta con una sola pantalla del tamaño de un libro estándar y puede contener entre 4.000 y 36.000 páginas de texto e imágenes en sus $4 \mathrm{MB}$, el equivalente a 10 novelas. $\mathrm{Su}$ pantalla es monocroma de alto contraste y resolución, contando con luz trasera, lo que le permite leer con poca luz o a pleno sol. Además cuenta con dos tamaños de fuente para elegir el tipo de caracteres y la opción de leer con la página en la posición horizontal. $\mathrm{Su}$ batería recargable de ion-litio le da una autonomía de 20 a 40 horas.

\section{«El libro electrónico ha pasado de supuestamente 'extinguir' al libro físico durante una época a ser un valor a la baja, dando al traste con diversas empresas"}

Fue, y es, muy popular, siendo el más frecuentemente utilizado por las bibliotecas norteamericanas para ser prestado con textos precargados, dentro de algunas iniciativas de evaluación de su uso. Permite incluir anotaciones en el texto gracias a un teclado que aparece en la pantalla al activar un icono, así como un punzón. Carga el libro a través de un PC, utilizando su disco duro de intermediario entre la librería virtual y su libro electrónico.

-Everybook: en 1995, Daniel E. Munyan funda la empresa Everybook Inc. que 5 años más tarde crea el Everybook Dedicated Reader. El concepto en el cual se basa es completamente diferente, ya que tiene 2 pantallas enfrentadas en color que se asemejaban a un libro abierto y en su momento estaba orientada a las reproducciones de alta calidad de libros de gráficos e imágenes. Estas pantallas son táctiles y del tamaño de 
una hoja A4, dispone de una memoria capaz de almacenar 50.000 páginas $\mathrm{y}$, a diferencia de sus predecesores, puede leer ficheros pdf, lo cual es un acierto ya que es un formato muy utilizado en transmisiones de documentos. Era por todo ello el más caro (1.600 US\$) pero tenía previsto lanzar en el año 2000 una versión un poco más pequeña y algo más barata (750 US\$).

En esta temprana época de finales de siglo, se produce una verdadera edad de oro de los ebooks con la aparición desordenada y simultánea de todos estos distintos aparatos. A ello contribuye enormemente la decisión del famoso escritor de novelas de terror Stephen King de publicar su obra Riding the bullet, exclusivamente en soporte electrónico. El 13 de marzo de 1999, apoyado por la editorial Simon \& Schuster, King se compromete a difundir por internet más novelas si el $75 \%$ de los internautas que se descargaban la novela pagaban los 2,5 US\$ que costaba. En solo 48 horas, 500.000 usuarios la compraron. En España Arturo Pérez Reverte presentó en internet su segunda entrega de El Capitán Alatriste, El oro del Rey, antes de difundirlo en formato papel. El texto electrónico costaba 500 PTA y logró registrar 4.000 descargas.

En 2000, Stephen King probó de nuevo con The plant y anunció que seguiría construyendo la historia siempre y cuando el número de usuarios que pagara al descargarse el capítulo alcanzara el 75\%. La cosa empezó bien, pero King tuvo que desistir en el capítulo 6 ya que cada vez eran menos los internautas que pagaban. Pero la iniciativa dejó ver que este método acercaba a autor y lector de muchas maneras.

En el año 2000, la compañía Gemstar-TV Guide International Group adquiere las dos empresas más potentes y pioneras en la fabricación de libros electrónicos: Softbook Press Inc. y Nuvomedia Inc., erigiéndose como uno de los grandes del sector. Los primeros aparatos que salen al mercado son el REB 1100 que sustituye al antiguo Rocket e-Book, y el REB1200 que sucede al Softbook. Los modelos 1100 y 1200 pesan al- rededor de 600 y 900 gramos respectivamente y cuentan con una batería que, dependiendo de si se utiliza con luz ambiente o de la propia pantalla, le proporciona una autonomía de entre 20 y 35 horas, recargándose en unos 90 minutos. Estos dos aparatos son muy similares a los que sustituyen; sólo hay algunas pequeñas diferencias de peso y dimensiones, ya que la pantalla del REB1200 es en color. (Aquí hemos nombrado lo aparatos lectores más comunes pero existen otros, como por ejemplo el francés Cytale, el italiano $M y$ Friend o el coreano Hiebook).

En 2002 Gemstar lanzaría al mercado los $G E B 1150$ y $G E B 2150$ que reemplazan a los modelos comentados en el párrafo anterior. Prácticamente no aportan ninguna novedad. Al igual que sus predecesores, ambos cuentan con una memoria de $8 \mathrm{MB}$, el equivalente a unas 8.000 páginas de texto aunque es posible expandirla a $128 \mathrm{MB}$. La pantalla del GEB2150 es en color y más grande. Una de las mejores herramientas disponibles en los anteriores Rocket Readers era el RocketWriter, que permitía a los usuarios formatear sus propios textos escritos con cualquier programa de tratamiento de textos y poder cargarlos dentro del Rocket. Estas nuevas versiones del lector no contaron con esta utilidad.

\section{El e-ink}

En 1998 Nicolas Negroponte informó en un seminario sobre los experimentos llevados a cabo en el célebre Laboratorio de Medios del Massachusetts Institute of Technology (MIT) en torno al "papel electrónico" y a la "tinta electrónica". Se trata de unas pantallas ultrafinas del grosor de una cartulina, flexibles y enrollables. Estas láminas tienen insertadas millones de diminutas microesferas que, como respuesta a una variación del campo electromagnético, pueden girar mostrando uno de sus hemisferios, cambiando de color de blanco a negro. Estos puntitos van formando letras, palabras, párrafos, etc., y estas páginas pueden ser escritas y luego borradas. La calidad de la imagen es supe-

Taylor \& Francis The Netherlands, editora de esta revista, tiene encargada la distribución de sus publicaciones a la siguiente empresa:

Extenza-Turpin. Stratton Business Park, Pegasus D rive, Biggleswade, Bedfordshire SG 18 8Q B, Reino U nido. Servicio usuarios: Tel.: +44-1767-60 4951

Centralita: Tel.: +44-1767-60 4800

Fax: +44-1767-60 16

subscriptions@ extenza-turpin.com

Rogamos a nuestros suscriptores que para solventar cualquier asunto administrativo se dirijan siempre directamente a Extenza-Turpin. Recordamos que continúan en funcionamiento los números de teléfo no de atención al suscriptor en Barcelona:

Tel.: +34-932081 970; fax: 932081971 
rior a la de una pantalla de cristal líquido y similar a la de una impresora láser. Su ángulo de visión es muy ancho y se prevé hacerlo en color. Su capacidad es enorme y según sus creadores podrá almacenar en un solo volumen el equivalente a estanterías completas de sus análogos de celulosa; e incluso se podrá dar animación a las imágenes. Son varias las iniciativas que han aparecido, como el Gyricon de Xerox o el Inmedia del propio MIT.

IBM ganó la medalla de oro de la Sociedad de Diseño Industrial de EUA en 1999 por un proyecto de periódico electrónico de 16 páginas que permite ser personalizado por las necesidades de los lectores.

\section{PDAs}

Se llaman organizadores digitales, PDAs o Palms $P C$ s y han tenido una amplia difusión entre el público en general. Estos microordenadores poseen la misma potencia que sus hermanos mayores, pero caben en una mano, tienen más autonomía que los ordenadores portátiles y pueden ser transportados en el bolsillo. Utilizados como libros electrónicos son muy útiles y permiten incluso reproducir imágenes en movimiento y sonidos, con la posibilidad de conectarse a internet. Existen muchos programas para ellos: procesadores de textos, bases de datos, agendas electrónicas, etc.

\section{Nota final}

Esta breve revisión a los sucesivos pasos que ha dado la edición electrónica dentro de su historia ha estado sujeta a una serie de períodos y sucesivos vaivenes. En esta andadura, el libro electrónico ha pasado de "extinguir" al libro físico durante una época a ser un valor a la baja, dando al traste con diversas empresas. Es obvio que la edición electrónica facilita la rápida elaboración de ejemplares y su difusión por todo el mundo gracias a las redes de comunicación. Pero es precisamente esta facilidad de hacer copias que puede inducir al pirateo, junto a la diversidad y multiplicidad de formatos propietarios, incompatibles entre sí, la falta de abaratamiento de estas ediciones, etc., lo que siembra la desconfianza hacia el libro electrónico, entre los editores y entre los lectores.

En la edición electrónica aún no se ha escrito la última palabra; esta historia es mucho más larga, veremos lo que nos depara el futuro.

\section{Bibliografía}

Abadal Falgueras, Ernest. Sistemas y servicios de información digital. Gijón: Trea, 2001.

Banerji, Ashok. Electronic library of the future. Consultado en: julio de 2002.

http://web.singnet.com.sg/ abanerji/sect1.htm\#EBOOK

http://web.singnet.com.sg/ abanerji/sect3.htm
Biblioteca Virtual Miguel de Cervantes. Consultado en: diciembre de 2003.

http://cervantesvirtual.com

Breton, Philippe. Historia y crítica de la informática. Madrid: Cátedra, 1989.

Bush, Vannebar. "As we may think". En: Atlantic Monthly. Consultado en: febrero de 2003.

http://www.theatlantic.com/unbound/flashbks/computer/bushf.htm

Campbell-Kelly, Martin. Computer: a history of information machine. New York: Basic Books, 1996.

Can e-books improve libraries?. Consultado en: noviembre de 2001. http://skyways.lib.ks.us/central/ebooks/libraries.html

Codina, Lluís. El libro digital y la www. España: Tauro, 2000.

Codina, Lluís. "Las propiedades de la información digital”. En: El profesional de la información (2001), nov.-dic., v. 10, n. 12, pp. 18-25.

Díaz Noci, Javier. La escritura digital: hipertexto y construcción del discurso informativo en el periodismo electrónico. Universidad del País Vasco, 2001.

Electronic Text Center de la Universidad de Virginia. Consultado en: diciembre de 2003.

http://etext.lib.virginia.edu/

Figueroa Alcántara, H. A.; Lara Pacheco, C. G. "El proyecto Xanadú: utopía vigente en el entorno del acceso a la información". En: Nueva época, 2000, julio-diciembre, v. 3, n. 2, pp. 92-99.

Gallica. Consultado en: diciembre de 2003.

http://gallica.bnf.fr/

Hípola, Pedro; Eíto Brun, Ricardo. "Edición digital: formatos y alternativas". En: El profesional de la información, 2000, octubre, v. 9, n. 10, pp. 4-15.

Landauer, Thomas [et al.]. Enhancing the usability of text through computer delivery and formative evaluation: the SuperBook Project. Consultado en: octubre de 2002.

http://telecaster.lboro.ac.uk/HaPP/chapter5.html

Lewis, Michael. The new new thing: a Silicon Valley story. London: Hodder \& Stoughton, 1999.

Licklider, Joseph Carl Robnett. Libraries of the future. Cambridge: The MIT Press, 1965.

Millán, José Antonio. Edición electrónica. Libros y bitios. http://jamillan.com

Nelson, Theodor. Literary machines. Sausalito, CA: Mindful Press, 1981 y 1993.

Open eBook Forum. Consultado en: diciembre de 2003.

http://www.openebook.org

Proyecto Gutenberg. Consultado en: diciembre de 2003.

http://sailor.gutenberg.org

http://promo.net/pg

Sáez Vacas, Fernando.

http://www.gsi.dit.upm.es/ fsaez/elhombre/pcweek016p.html

Tomàs i Puig, Carles. Del hipertexto al hipermedia. Una aproximación al desarrollo de las obras abiertas. Consultado en: febrero de 2003.

http://www.iua.upf.es/formats/formats2/tom_e.htm

Wilson, Ruth. Evolution of portable electronic books. Consultado en: junio de 2002.

http://www.ariadne.ac.uk/issue29/wilson/

Xanadú. Consultado en: diciembre de 2003.

http://www.xanadu.com

Fernando Pérez Arranz, biblioteca de la Universidad de Alcalá de Henares.

fernando.perez@uah.es 